\title{
SYNTHESIS OF 5-SUBSTITUTED 2'-DEOXYURIDINE-5'- PHOSPHONATE ANALOGUES AND EVALUATION OF THEIR ANTIVIRAL ACTIVITY
}

Sara Van Poecke, ${ }^{\mathrm{a}}$ Davy Sinnaeve, ${ }^{\mathrm{b}}$ José C. Martins, ${ }^{\mathrm{b}}$ Jan Balzarini, ${ }^{\mathrm{c}}$ and Serge Van Calenbergh ${ }^{\mathrm{a},{ }^{*}}$

${ }^{a}$ Laboratory for Medicinal Chemistry, Faculty of Pharmaceutical Sciences, Ghent University, Harelbekestraat 72, B-9000 Gent, Belgium, ${ }^{b}$ NMR and Structure Analysis Unit, Department of Organic Chemistry, Ghent University, Krijgslaan 281 S4, B-9000 Gent, Belgium, ${ }^{c}$ Rega Institute for Medical Research, Katholieke Universiteit Leuven, B-3000 Leuven, Belgium.

*correspondence to Prof. Serge Van Calenbergh, Ghent University, Faculty of Pharmaceutical Sciences, Laboratory for Medicinal Chemistry, Harelbekestraat 72, B9000 Gent, Belgium, Tel +32 9264 81 24, Fax +329264 8146. 


\title{
SYNTHESIS OF 5-SUBSTITUTED 2'-DEOXYURIDINE ANALOGUES AND EVALUATION OF THEIR ANTIVIRAL ACTIVITY
}

\begin{abstract}
A small series of 5-(hetero)aryl-modified nucleoside phosphonates was synthesized via an 8-step procedure including a Wittig reaction and SuzukiMiyaura coupling. An unanticipated anomerisation during phosphonate deprotection allowed us to isolate both anomers of the 5-substituted 2'-deoxyuridine phosphonates and assess their antiviral activity against a broad panel of viruses.
\end{abstract}

Keywords: antiviral nucleoside analogues, pyrimidine modification, phosphonates, $\alpha$-nucleosides, antiviral activity

\section{Introduction}

Antiviral drugs have become crucial in the management of several viral infections, including human HSV, HIV, HBV, HCV and cytomegalovirus (HCMV) infections. Prominent among these drugs are nucleoside analogues, which can act as potent antiviral agents owing to their ability to inhibit viral polymerases. ${ }^{1}$ Many publications have appeared on the synthesis and antiviral activity of 5-modified 2'-deoxyuridine analogues. Several substituents have been introduced at C-5, including alkoxymethyl groups, ${ }^{2}$ azoles $^{3}$ and alkyloximes. ${ }^{3}$ Several analogues proved moderately to highly active against HSV. These results showed that modification at position 5 of 2'deoxyuridine represents an interesting approach in the search for new anti-herpes agents. However, relatively few examples of 5-(hetero)aryl-modified nucleosides with promising antiviral activity have been reported. ${ }^{4}$ This may be due to the fact that these 
nucleosides are not efficiently converted into their triphosphate form. The first step in this process, the phosphorylation of the nucleoside analogue into its 5'-monophosphate counterpart by nucleoside kinases, is often rate-limiting in the conversion to the active metabolite. One way to overcome this bottleneck is to devise prodrugs that are capable of delivering the nucleoside monophosphate intracellularly. ${ }^{5,6}$ Another approach to bypass the first phosphorylation step is to use phosphonate analogues, that, after intracellular conversion into their corresponding diphosphophosphonate forms, can exhibit antiviral activities. This led us to investigate a small series of 2'-deoxyuridine analogues that combine different aromatic substituents at position 5 of the base with a 5'-methylene phosphonate group.

\section{Results and discussion}

The synthesis of a series of 5-(hetero)aryl-modified nucleoside phosphonates started from 3'-O-tert-butyldimethylsilyl-2'-deoxy- $\beta$-D-uridine ${ }^{7}$ and is depicted in Scheme 1. Conversion of nucleoside 6 to the vinylic phosphonate 7 was accomplished following the two-step procedure described by Cosyn et al. ${ }^{8}$ Catalytic hydrogenation of 7 in the presence of $\mathrm{Pd} / \mathrm{C}$ afforded phosphonate $\mathbf{8}$ which was selectively brominated at C-5 of the pyrimidine moiety using $N$-bromosuccinimide in DMF. ${ }^{9}$ Palladium-catalyzed cross-coupling with four commercial aryl and heteroaryl boronic acids gave access to 10-13. ${ }^{10}$ After removing the silyl protecting group, deprotection of the phosphonate esters was performed using TMSBr in $\mathrm{CH}_{2} \mathrm{Cl}_{2}$. Concomitant anomerisation during this last step resulted for each analogue in a 2:1 mixture of the $\alpha$ - and $\beta$-isomer, which could be separated using RP-HPLC. Stereochemical assignment of compound 1a was based on the results of a ROESY experiment (Figure 3). A clear rOe contact between H-4' and $\mathrm{H}-2$ 'b (proton down) and a much weaker interaction between $\mathrm{H}-6$ and $\mathrm{H}-2$ ' $\mathrm{b}$ proved that 
H-4' and H-6 were not positioned at the same side of the furanose ring. The $\beta$ configuration of the nucleobase was further established by the presence of a strong interaction between H-6 and H-5'a,b.

In an effort to synthesize the non-modified 2'-deoxyuridine-5'-phosphonate analogue, compound $\mathbf{8}$ was successively treated with a $1 \mathrm{M}$ TBAF solution in THF and TMSBr in $\mathrm{CH}_{2} \mathrm{Cl}_{2}$ (Scheme 2). In this case, attempts to separate the anomeric mixture using flash chromatography and RP-HPLC were unsuccessful. To avoid the anomerisation issue, we attempted to deprotect $\mathbf{1 8}$ in the presence of TMSBr under different reaction conditions. Following the reaction via ${ }^{31} \mathrm{P} \mathrm{NMR}$, it was observed that anomerisation started immediately after addition of TMSBr. We learned by attempts at different temperatures that no reaction occurred under $-20{ }^{\circ} \mathrm{C}$, and that anomerisation started simultaneously with the phosphonate hydrolysis, even at low temperature. Also the addition of an acid scavenger (e.g., (trimethylsilyl)acetamide or 2,6-lutidine) could not prevent anomerisation. ${ }^{11}$

All compounds were evaluated for their antiviral activity against a broad panel of viruses including HSV-1 (KOS), HSV-2 (G), vaccinia virus (VV), vesicular stomatitis virus (VSV), thymidine kinase deficient HSV-1 TK- $\left(\mathrm{KOS} \mathrm{ACV}^{\mathrm{r}}\right), \mathrm{HCMV}$ and VZV in HEL (human embryonic lung) cell cultures; and HIV-1 (III $\left.\mathrm{B}_{\mathrm{B}}\right)$ and HIV-2 (ROD) in human T-lymphocyte (CEM) cell cultures. The activities of the compounds were compared with reference antiviral drugs: brivudin, cidofovir, acyclovir and ganciclovir.

None of the tested compounds showed toxicity to any of the tested cell lines. However, the final compounds $\mathbf{1} \mathbf{a}-\mathbf{4 a}$ and $\mathbf{1 b}-\mathbf{4 b}$ failed to show antiviral activity against HSV-1, HSV-2, VV, VSV, HSV-1 TK ${ }^{-}$and different VZV strains. Also in the human Tlymphocyte (CEM) cell cultures, none of these compounds showed activity against 
HIV-1 or HIV-2. Very weak antiviral activity was observed for the $\beta$-analogue 3a and the $\alpha$-analogue 2b against HCMV Davies and HCMV AD-169, respectively, while compounds 2a and 4a showed weak activity against both HCMV strains (Table 1). The most active compound of this series, analogue $\mathbf{2 a}$, was at least 6 or 50 times less active than ganciclovir and cidofovir, respectively. The lack of biological activity of these derivatives might be attributed to several features, including 1) their inability to diffuse through the cell membrane; 2) their ineffective conversion to the corresponding diphosphophosphonate analogue; or 3) their weak affinity for the target polymerases and/or lack of incorporation into viral RNA. If uptake into the cell would be the bottleneck, converting the phosphonates to an appropriate prodrug form could be considered.

\section{Conclusion}

In conclusion, this study described the synthesis, structural analysis and antiviral activity of a small series of 2'-deoxyuridine analogues that combine different aromatic substituents at position 5 of the base and a 5'-methylene phosphonate modification at the sugar moiety. All compounds were synthesized via an 8-step procedure, featuring a Wittig reaction and Suzuki-Miyaura coupling. An unexpected anomerisation during the last step of the synthesis allowed us to investigate the $\beta$ - as well as the $\alpha$-anomers of the corresponding phosphonates. None of these analogues exhibited significant antiviral activity

Acknowledgements, We thank the Institute for the Promotion of Innovation by Science and Technology in Flanders (IWT) for providing a scholarships to SVP. The antiviral research was supported by the K.U.Leuven (GOA no. 10/14). We also thank Mrs. Leen Ingels, Leentje Persoons, Frieda De Meyer, Anita Camps, Lies Van den Heurck and Mr. Steven Carmans for technical assistance in the antiviral experiments. 


\section{Experimental section}

Synthesis. General. All reagents were from standard commercial sources and of analytical grade. Precoated Merck silica gel F254 plates were purchased for TLC, spots were examined under ultraviolet light at $254 \mathrm{~nm}$ and further visualized by sulfuric acidanisaldehyde spray. Column chromatography was performed on silica gel (63-200 $\mu \mathrm{m}$, $60 \AA$, Biosolve, Valkenswaard, The Netherlands). With the exception of the ${ }^{13} \mathrm{C}$ NMR spectrum of compound 1a, which was recorded on a $500 \mathrm{MHz}$ Bruker DRX apparatus, all NMR spectra were determined using a Varian Mercury $300 \mathrm{MHz}$ spectrometer. Chemical shifts are given in ppm $(\delta)$ relative to the residual solvent signals, which in the case of DMSO- $d_{6}$ were $2.54 \mathrm{ppm}$ for ${ }^{1} \mathrm{H}$ and $40.5 \mathrm{ppm}$ for ${ }^{13} \mathrm{C}$. Structural assignment was confirmed with COSY and DEPT. All signals assigned to hydroxyl groups were exchangeable with $\mathrm{D}_{2} \mathrm{O}$. Exact mass measurements were performed on a Waters LCT Premier XETM Time of flight (TOF) mass spectrometer equipped with a standard electrospray ionization (ESI) and modular LockSpray TM interface. Samples were infused in a $\mathrm{CH}_{3} \mathrm{CN} /$ water $(1: 1)$ mixture at $10 \mu \mathrm{L} / \mathrm{min}$.

\section{1-[3-O-tert-Butyldimethylsilyl-2,5,6-trideoxy-6-(diethoxyphosphinyl)- $\beta$-D-hex-5-}

enofuranosyl]-uracil (7). 2'-Iodoxybenzoic acid (550 $\mathrm{mg}, 1.97 \mathrm{mmol}$ ) was added to a solution of 6 (449 mg, $1.31 \mathrm{mmol})$ in $\mathrm{CH}_{3} \mathrm{CN}(12 \mathrm{~mL})$ and the resulted suspension was stirred at $80{ }^{\circ} \mathrm{C}$ for $6 \mathrm{~h}$. After cooling in an ice bath $(15 \mathrm{~min})$, the solid was removed by filtration and washed with cold $\mathrm{CH}_{3} \mathrm{CN}$. The solvent was evaporated and the residue was co-distilled with toluene. The residue was dissolved in anhydrous DMSO (3.4 mL) and freshly prepared [(diethoxyphosphinyl)methyl]triphenylphosphorane in DMSO (3.4 $\mathrm{mL}$ ) was added. After $20 \mathrm{~h}$, the mixture was poured into water and extracted with $\mathrm{CH}_{2} \mathrm{Cl}_{2}$. The combined organic layers were dried over $\mathrm{MgSO}_{4}$, filtered and concentrated 
in vacuo. The residue was lyophilized to remove the remaining DMSO and purified on a silica gel column $\left(\mathrm{CH}_{2} \mathrm{Cl}_{2} / \mathrm{MeOH} 98: 2\right)$ yielding $257 \mathrm{mg}(41 \%)$ of 7 as a colourless solid. ${ }^{1} \mathrm{H}$ NMR (300 MHz, DMSO- $\left.d_{6}\right): \delta 0.070$ (6H, s, TBDMS), 0.87 (9H, s, TBDMS), $1.23\left(6 \mathrm{H}\right.$, app dt, $\left.J=1.5 \mathrm{~Hz}, J=6.9 \mathrm{~Hz}, 2 \times \mathrm{OCH}_{2} \mathrm{CH}_{3}\right), 2.13-2.22(1 \mathrm{H}, \mathrm{m}, \mathrm{H}-2$ 'a), 2.342.43 (1H, m, H-2’b), 3.92-4.03 (4H, m, 2 x $\left.\mathrm{OCH}_{2} \mathrm{CH}_{3}\right), 4.20-4.25$ (1H, m, H-4'), 4.38$4.45(1 \mathrm{H}, \mathrm{m}, \mathrm{H}-3$ ') $5.64(1 \mathrm{H}, \mathrm{d}, J=7.8 \mathrm{~Hz}, \mathrm{CH}=\mathrm{CH}), 5.96-6.09$ (1H, m, H-6'), 6.16 $\left(1 \mathrm{H}, \mathrm{dd}, J=6.0 \mathrm{~Hz}, J=7.5 \mathrm{~Hz}, \mathrm{H}-1^{\prime}\right), 6.60-6.75$ (1H, m, H-5'), 7.68 (1H, d, $J=8.4 \mathrm{~Hz}$,

$\mathrm{CH}=\mathrm{CH}), 11.34(1 \mathrm{H}, \mathrm{s}, 3-\mathrm{NH}) .{ }^{31} \mathrm{P}$ NMR $\left(\mathrm{DMSO}-d_{6}\right): \delta 17.21 .{ }^{13} \mathrm{C}$ NMR $(75 \mathrm{MHz}$, DMSO- $\left.d_{6}\right): \delta-5.02,-4.87$ (TBDMS), 16.10, $16.18\left(\mathrm{OCH}_{2} \mathrm{CH}_{3}\right), 17.60$ (TBDMS), 25.57 (TBDMS), 61.21, $61.31\left(\mathrm{OCH}_{2} \mathrm{CH}_{3}\right), 74.36$ (C-3'), 84.27 (C-1'), 85.27 (C-4', d, J= 23 Hz), 102.07 (C-5), 119.70 (C-6', d, $J=182 \mathrm{~Hz}), 141.38$ (C-6), 147.81 (C-5', d, $J=5$ $\mathrm{Hz}$ ), 150.29 (C-2), 162.98 (C-4). Exact mass (ESI-MS) for $\mathrm{C}_{20} \mathrm{H}_{36} \mathrm{~N}_{2} \mathrm{O}_{7} \mathrm{PSi}[\mathrm{M}+\mathrm{H}]^{+}$ found, 475.2035; calcd, 475.2024.

\section{1-[3-O-tert-Butyldimethylsilyl-2,5,6-trideoxy-6-(diethoxyphosphinyl)- $\beta$-D-}

hexofuranosyl]-uracil (8). To a solution of compound $7(257 \mathrm{mg}, 0.54 \mathrm{mmol})$ in $\mathrm{MeOH}(8 \mathrm{~mL})$ was added $10 \% \mathrm{Pd} / \mathrm{C}$. The reaction mixture was stirred under hydrogen atmosphere overnight. The catalyst was removed by filtration through Celite and the filtrate was evaporated to yield pure compound $8(250 \mathrm{mg}, 97 \%)$ as a colourless solid. ${ }^{1} \mathrm{H}$ NMR (300 MHz, DMSO- $\left.d_{6}\right): \delta 0.084$ (6H, app d, $\left.J=2.4 \mathrm{~Hz}, \mathrm{TBDMS}\right), 0.87$ (9H, s, TBDMS), $1.22\left(6 \mathrm{H}, \mathrm{t}, J=6.9 \mathrm{~Hz}, 2\right.$ x $\left.\mathrm{OCH}_{2} \mathrm{CH}_{3}\right), 1.65-1.86$ (4H, m, H-5'a, H-5'b, H6'a and H-6'b), 2.00-2.15 (1H, m, H-2'a), 2.22-2.31 (1H, m, H-2'b), 3.68-3.72 (1H, m, H-3'), 3.92-4.04 (4H, m, 2 x $\left.O \mathrm{CH}_{2} \mathrm{CH}_{3}\right), 4.23-4.29(1 \mathrm{H}, \mathrm{m}, \mathrm{H}-4$ '), $5.62(1 \mathrm{H}, \mathrm{d}, J=8.1$ $\mathrm{Hz}, \mathrm{CH}=\mathrm{CH}), 6.10\left(1 \mathrm{H}, \mathrm{t}, J=6.6 \mathrm{~Hz}, \mathrm{H}-1^{\prime}\right), 7.59(1 \mathrm{H}, \mathrm{d}, J=8.4 \mathrm{~Hz}, \mathrm{CH}=\mathrm{CH}), 11.32$ $(1 \mathrm{H}, \mathrm{s}, 3-\mathrm{NH}) .{ }^{31} \mathrm{P}$ NMR (DMSO- $\left.d_{6}\right): \delta 31.72 .{ }^{13} \mathrm{C}$ NMR $\left(75 \mathrm{MHz}, \mathrm{DMSO}-d_{6}\right): \delta-5.04,-$ 4.99 and -4.73 (TBDMS), 16.21 and $16.28\left(\mathrm{OCH}_{2} \mathrm{CH}_{3}\right)_{2}, 17.58$ (TBDMS), 20.97 (C-6', 
d, $J=139 \mathrm{~Hz}),, 25.69\left(\mathrm{C}^{\prime}, \mathrm{d}, J=12 \mathrm{~Hz}\right), 60.90,60.97\left(\mathrm{OCH}_{2} \mathrm{CH}_{3}\right)_{2}, 73.84\left(\mathrm{C}-3^{\prime}\right), 84.95$ (C-4', d, $J=16$ Hz), 83.61 (C-1'), 102.10 (C-5), 141.03 (C-6), 150.40 (C-2), 163.11 (C4). Exact mass (ESI-MS) for $\mathrm{C}_{20} \mathrm{H}_{38} \mathrm{~N}_{2} \mathrm{O}_{7} \mathrm{PSi}[\mathrm{M}+\mathrm{H}]^{+}$found, 477.2119; calcd, 477.2180. 1-[3-O-tert-Butyldimethylsilyl-2,5,6-trideoxy-6-(diethoxyphosphinyl)- $\beta$-Dhexofuranosyl]-5-bromouracil (9). To a solution of compound 8 (950 mg, $1.99 \mathrm{mmol})$ in DMF (15 mL) was added $N$-bromosuccinimide (NBS, $390 \mathrm{mg}, 2.19 \mathrm{mmol}$ ) under $\mathrm{N}_{2}$. The reaction mixture was stirred at room temperature for 16 hours. DMF was removed in vacuo and the residue was purified by column chromatography $\left(\mathrm{CH}_{2} \mathrm{Cl}_{2} / \mathrm{MeOH} 97: 3\right)$ to afford $9(538 \mathrm{mg}, 49 \%)$ as a white foam. ${ }^{1} \mathrm{H}$ NMR $\left(300 \mathrm{MHz}, \mathrm{CDCl}_{3}\right): \delta 0.082(6 \mathrm{H}$, app d, $J=1.8 \mathrm{~Hz}$, TBDMS), $0.89(9 \mathrm{H}, \mathrm{s}, \mathrm{TBDMS}), 1.34(6 \mathrm{H}, \mathrm{t}, J=6.9 \mathrm{~Hz}, 2 \mathrm{x}$ $\left.\mathrm{OCH}_{2} \mathrm{CH}_{3}\right), 1.82-2.02$ (4H, m, H-5'a, H-5'b, H-6'a and H-6'b), 2.09-2.16 (1H, m, H2'a), 2.29-2.32 (1H, m, H-2’b), 3.81-3.84 (1H, m, H-4'), 4.07-4.19 (5H, m, 2 x

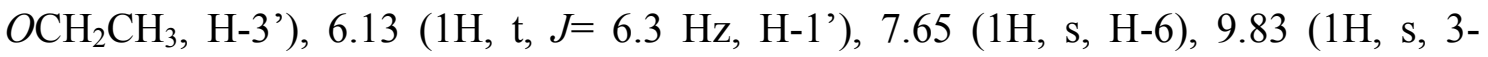
$\mathrm{NH}) .{ }^{31} \mathrm{P}$ NMR $\left(\mathrm{CDCl}_{3}\right): \delta 30.90 .{ }^{13} \mathrm{C} \mathrm{NMR}\left(75 \mathrm{MHz}, \mathrm{CDCl}_{3}\right): \delta-4.83,-4.56$ (TBDMS), 16.46, $16.54\left(\mathrm{OCH}_{2} \mathrm{CH}_{3}\right)_{2}, 17.89$ (TBDMS), 22.33 (C-6', d, $\left.J=143 \mathrm{~Hz}\right), 25.68$ (TBDMS), 26.56 (C-5', d, $J=4.1 \mathrm{~Hz}), 40.85\left(\mathrm{C}-2^{\prime}\right), 61.80,61.83\left(\mathrm{OCH}_{2} \mathrm{CH}_{3}\right)_{2}, 74.50$ (C-3'), 85.57 (C-1'), 86.53 (C-4', d, $J=17.0$ Hz), 97.10 (C-5), 139.01 (C-6), 149.47 (C2), 159.03 (C-4). Exact mass (ESI-MS) for $\mathrm{C}_{20} \mathrm{H}_{37} \mathrm{BrN}_{2} \mathrm{O}_{7} \mathrm{PSi}[\mathrm{M}+\mathrm{H}]^{+}$found, 555.1323; calcd, 555.1286 .

General procedure for the synthesis of 5-modified nucleoside phosphonates via Suzuki-Miyaura coupling . A mixture of compound 9 (1 equiv.), aryl boronic acid (2 equiv.), $\mathrm{Pd}\left(\mathrm{PPh}_{3}\right)_{4}$ (0.1 equiv.) and $\mathrm{Na}_{2} \mathrm{CO}_{3}$ (3.3 equiv.) in DMF and degassed $\mathrm{H}_{2} \mathrm{O}$ was heated $\left( \pm 130{ }^{\circ} \mathrm{C}\right.$, oil bath) under argon for $6 \mathrm{~h}$ or until TLC indicated consumption of all starting material. The mixture was then concentrated and co-distilled with toluene. 
The residue was purified by column chromatography $\left(\mathrm{CH}_{2} \mathrm{Cl}_{2} / \mathrm{MeOH}\right.$ 94:6-98:2) affording the 5-modified analogues in moderate yield.

\section{1-[3-O-tert-Butyldimethylsilyl-2,5,6-trideoxy-6-(diethoxyphosphinyl)-ß-D-}

hexofuranosyl]-5-phenyluracil (10). Reaction of compound 9 (153 mg, $0.27 \mathrm{mmol})$ with phenylboronic acid $(68 \mathrm{mg}, 0.55 \mathrm{mmol}), \mathrm{Pd}\left(\mathrm{PPh}_{3}\right)_{4}(32 \mathrm{mg}, 0.027 \mathrm{mmol})$ and $\mathrm{Na}_{2} \mathrm{CO}_{3}(96 \mathrm{mg}, 0.91 \mathrm{mmol})$ in $\operatorname{DMF}(6.5 \mathrm{~mL})$ and degassed $\mathrm{H}_{2} \mathrm{O}(0.8 \mathrm{~mL})$ was performed as described in the general procedure to yield compound $\mathbf{1 0}$ as a colourless solid (120 mg, 79\%). ${ }^{1} \mathrm{H}$ NMR (300 MHz, $\left.\mathrm{CDCl}_{3}\right): \delta 0.084(6 \mathrm{H}, \mathrm{s}, \mathrm{TBDMS}), 0.90(9 \mathrm{H}$, s, TBDMS), 1.25-1.32 (6H, m, 2 x $\left.\mathrm{OCH}_{2} \mathrm{CH}_{3}\right), 1.73-2.04$ (4H, m, H-5'a, H-5'b, H-6'a and H-6’b), 2.11-2.20 (1H, m, H-2'a), 2.31-2.39 (1H, m, H-2'b), 3.83-3.86 (1H, m, H4'), 4.00-4.11 (5H, m, 2 x $O \mathrm{OCH}_{2} \mathrm{CH}_{3}$ and H-3'), 6.23 (1H, app t, $\left.J=6.6 \mathrm{~Hz}, \mathrm{H}-1^{\prime}\right), 7.33-$ $7.71\left(6 \mathrm{H}, \mathrm{m}, \mathrm{Ph}\right.$ and H-6). ${ }^{31} \mathrm{P} \mathrm{NMR}\left(\mathrm{CDCl}_{3}\right): \delta 30.69 .{ }^{13} \mathrm{C} \mathrm{NMR}\left(75 \mathrm{MHz}, \mathrm{CDCl}_{3}\right): \delta$ 4.73 and -4.46 (TBDMS), 16.48, $16.56\left(\mathrm{OCH}_{2} \mathrm{CH}_{3}\right)_{2}, 18.00$ (TBDMS), 22.39 (C-6', d, $J=143 \mathrm{~Hz}$ ), 25.80 (TBDMS), 26.60 (C-5', d, $J=4.4 \mathrm{~Hz}), 40.67$ (C-2'), 61.89 and 61.92 $\left(\left(\mathrm{OCH}_{2} \mathrm{CH}_{3}\right)_{2}, \mathrm{~d}, J=6.5 \mathrm{~Hz}, 74.75\right.$ (C-3'), 85.30 (C-1'), 86.42 (C-4', d, $\left.J=17.0 \mathrm{~Hz}\right)$, 115.67 (C-5), 128.07-133.10 (Ph), 136.95 (C-6), 150.02 (C-2), 162.39 (C-4). Exact mass (ESI-MS) for $\mathrm{C}_{26} \mathrm{H}_{42} \mathrm{~N}_{2} \mathrm{O}_{7} \mathrm{PSi}[\mathrm{M}+\mathrm{H}]^{+}$found, 553.2485; calcd, 553.2493.

\section{1-[3-O-tert-Butyldimethylsilyl-2,5,6-trideoxy-6-(diethoxyphosphinyl)- $\beta$-D-}

hexofuranosyl]-5-(naphthalen-1-yl)uracil (11). Reaction of compound 9 (122 mg, $0.22 \mathrm{mmol})$ with naphthalene-1-boronic acid (75 mg, $0.44 \mathrm{mmol}), \mathrm{Pd}\left(\mathrm{PPh}_{3}\right)_{4}(25 \mathrm{mg}$, $0.022 \mathrm{mmol})$ and $\mathrm{Na}_{2} \mathrm{CO}_{3}(77 \mathrm{mg}, 0.72 \mathrm{mmol})$ in $\mathrm{DMF}(5 \mathrm{~mL})$ and degassed $\mathrm{H}_{2} \mathrm{O}(0.7$ $\mathrm{mL}$ ) was performed as described in the general procedure to afford compound $\mathbf{1 1}$ as a colourless solid (120 mg, 91\%). ${ }^{1} \mathrm{H}$ NMR (300 MHz, $\left.\mathrm{CDCl}_{3}\right): \delta 0.056(6 \mathrm{H}, \mathrm{s}, \mathrm{TBDMS})$, 0.87 (9H, s, TBDMS), 1.15-1.24 (6H, m, 2 x $\left.O \mathrm{CH}_{2} \mathrm{CH}_{3}\right), 1.77-2.03$ (4H, m, H-5'a, H5'b, H-6'a and H-6'b), 2.12-2.18 (1H, m, H-2'a), 2.26-2.31 (1H, m, H-2'b), $3.82(1 \mathrm{H}$, 
app s, H-4'), 3.95-4.13 (5H, m, 2 x $\mathrm{OCH}_{2} \mathrm{CH}_{3}$ and $\left.\mathrm{H}^{-3} 3^{\prime}\right), 6.24(1 \mathrm{H}$, app t, $J=6.6 \mathrm{~Hz}, \mathrm{H}-$ 1'), 7.42-7.82 (7H, m, naphthalene), 7.98 (1H, s, H-6), 8.43 (1H, s, 3-NH). ${ }^{31} \mathrm{P}$ NMR $\left(\mathrm{CDCl}_{3}\right): \delta 30.95 .{ }^{13} \mathrm{C} \mathrm{NMR}\left(75 \mathrm{MHz}, \mathrm{CDCl}_{3}\right): \delta-4.87$ and -4.62 (TBDMS), 16.2, 16.3 $\left(\mathrm{OCH}_{2} \mathrm{CH}_{3}\right), 17.85$ (TBDMS), 22.26 (C-6', d, $\left.J=143 \mathrm{~Hz}\right), 25.65$ (TBDMS), 23.46 (C5'), 40.50 (C-2'), 61.63, $61.71\left(\mathrm{OCH}_{2} \mathrm{CH}_{3}\right), 74.63$ (C-3'), 85.26 (C-1'), 86.29 (C-4', d, $J=17.0 \mathrm{~Hz}$ ), 115.45 (C-5), 125.89-133.22 (naphthalene), 136.91 (C-6), 149.88 (C-2), 162.26 (C-4). Exact mass (ESI-MS) for $\mathrm{C}_{30} \mathrm{H}_{44} \mathrm{FN}_{2} \mathrm{O}_{7} \mathrm{PSi}[\mathrm{M}+\mathrm{H}]^{+}$found, 603.2675; calcd, 603.2650 .

\section{1-[3-O-tert-Butyldimethylsilyl-2,5,6-trideoxy-6-(diethoxyphosphinyl)- $\beta$-D-}

hexofuranosyl]-5-(4-fluorophenyl)uracil (12). Reaction of compound 9 (163 mg, 0.29 mmol) with 4-fluorophenylboronic acid (82 mg, $0.59 \mathrm{mmol}), \mathrm{Pd}\left(\mathrm{PPh}_{3}\right)_{4}(34 \mathrm{mg}, 0.029$ mmol) and $\mathrm{Na}_{2} \mathrm{CO}_{3}(102 \mathrm{mg}, 0.97 \mathrm{mmol})$ in DMF $(7 \mathrm{~mL})$ and degassed $\mathrm{H}_{2} \mathrm{O}(0.9 \mathrm{~mL})$ was performed as described in the general procedure to yield compound $\mathbf{1 2}$ as a colourless solid (141 mg, 84\%). ${ }^{1} \mathrm{H}$ NMR (300 MHz, $\left.\mathrm{CDCl}_{3}\right): \delta 0.010$ (6H, s, TBDMS), 0.80-0.84 (9H, m, TBDMS), $1.21\left(6 \mathrm{H}\right.$, app q, $\left.J=7.2 \mathrm{~Hz}, 2 \times \mathrm{OCH}_{2} \mathrm{CH}_{3}\right), 1.68-1.94(4 \mathrm{H}$, m, H-5'a, H-5'b, H-6'a and H-6'b), 2.02-2.11 (1H, m, H-2'a), 2.23-2.31 (1H, m, H2’b), 3.74-3.78 (1H, m, H-4'), 3.93-4.02 (5H, m, 2 x $O^{\prime} \mathrm{CH}_{2} \mathrm{CH}_{3}$ and $\mathrm{H}-3$ ') $6.14(1 \mathrm{H}$, app t, $J=6.9 \mathrm{~Hz}, \mathrm{H}-1$ '), 6.99-7.04 (2H, m, subs Ph), 7.34-7.42 (3H, m, subs Ph and H6), $8.25(1 \mathrm{H}, \mathrm{s}, 3-\mathrm{NH}) .{ }^{31} \mathrm{P} \mathrm{NMR}\left(\mathrm{CDCl}_{3}\right): \delta 30.74 .{ }^{13} \mathrm{C} \mathrm{NMR}\left(75 \mathrm{MHz}, \mathrm{CDCl}_{3}\right): \delta-$ 4.59, -4.33 (TBDMS), 16.64, $16.72\left(\mathrm{OCH}_{2} \mathrm{CH}_{3}\right), 18.14$ (TBDMS), 22.65 (C-6', d, $J=$ $143 \mathrm{~Hz}), 25.91$ (TBDMS), 26.89 (C-5', d, $J=5.0 \mathrm{~Hz}), 40.95$ (C-2'), 61.89, 62.01 $\left(\mathrm{OCH}_{2} \mathrm{CH}_{3}\right), 74.89$ (C-3'), 85.60 (C-1'), 86.55 (C-4', d, J= $\left.17 \mathrm{~Hz}\right), 115.00$ (C-5), 128.42-132.40 (naphthalene), 136.74 (C-6), 149.55 (C-2), 161.72 (C-4). Exact mass (ESI-MS) for $\mathrm{C}_{26} \mathrm{H}_{41} \mathrm{FN}_{2} \mathrm{O}_{7} \mathrm{PSi}[\mathrm{M}+\mathrm{H}]^{+}$found, 571.2430; calcd, 571.2399. 


\section{1-[3-O-tert-Butyldimethylsilyl-2,5,6-trideoxy-6-(diethoxyphosphinyl)-ß-D-}

hexofuranosyl]-5-(thiophen-2-yl)uracil (13). Reaction of compound 9 (155 mg, 0.28 mmol) with thiophene-2-boronic acid (71 mg, $0.56 \mathrm{mmol}), \mathrm{Pd}\left(\mathrm{PPh}_{3}\right)_{4}(32 \mathrm{mg}, 0.028$ mmol) and $\mathrm{Na}_{2} \mathrm{CO}_{3}(98 \mathrm{mg}, 0.92 \mathrm{mmol})$ in DMF $(6.7 \mathrm{~mL})$ and degassed $\mathrm{H}_{2} \mathrm{O}(0.8 \mathrm{~mL})$ was performed as described in the general procedure to yield compound $\mathbf{1 3}$ as a colourless solid (117 mg, 75\%). ${ }^{1} \mathrm{H}$ NMR (300 MHz, $\left.\mathrm{CDCl}_{3}\right): \delta 0.090$ (6H, s, TBDMS), 0.90 (9H, s, TBDMS), 1.26-1.37 (6H, m, 2 x $\left.O \mathrm{CH}_{2} \mathrm{CH}_{3}\right), 1.83-2.08$ (4H, m, H-5'a, H5'b, H-6'a and H-6'b), 2.14-2.23 (1H, m, H-2'a), 2.32-2.40 (1H, m, H-2'b), 3.85-3.90 $\left(1 \mathrm{H}, \mathrm{m}, \mathrm{H}-4^{\prime}\right), 4.06-4.18\left(5 \mathrm{H}, \mathrm{m}, 2 \times \mathrm{OCH}_{2} \mathrm{CH}_{3}\right.$ and $\left.\mathrm{H}^{-3} 3^{\prime}\right), 6.23(1 \mathrm{H}$, app t, $J=6.3 \mathrm{~Hz}$, H-1'), 7.01-7.04 (1H, m, thiophene), 7.25-7.29 (1H, m, thiophene), 7.39-7.44 (1H, m, thiophene), $7.69(1 \mathrm{H}, \mathrm{s}, \mathrm{H}-6), 9.97(1 \mathrm{H}, \mathrm{s}, 3-\mathrm{NH}) .{ }^{31} \mathrm{P} \mathrm{NMR}\left(\mathrm{CDCl}_{3}\right): \delta 30.80 .{ }^{13} \mathrm{C} \mathrm{NMR}$ $\left(75 \mathrm{MHz}, \mathrm{CDCl}_{3}\right): \delta-4.77$ and -4.50 (TBDMS), 16.48, $16.56\left(\mathrm{OCH}_{2} \mathrm{CH}_{3}\right), 17.95$ (TBDMS), 22.36 (C-6', d, $J=143 \mathrm{~Hz}$ ), 25.74 (TBDMS), 26.69 (C-5', d, $J=4.7 \mathrm{~Hz}$ ), 40.91 (C-2'), 61.79, $61.86\left(\mathrm{OCH}_{2} \mathrm{CH}_{3}\right), 74.64$ (C-3'), 85.62 (C-1'), 86.55 (C-4', d, J= $16.8 \mathrm{~Hz}$ ), 110.20 (C-5), 124.42, 125.37, 127.10 and 133.63 (thiophene), 134.32 (C-6), 149.39 (C-2), 161.27 (C-4). Exact mass (ESI-MS) for $\mathrm{C}_{24} \mathrm{H}_{40} \mathrm{~N}_{2} \mathrm{O}_{7} \mathrm{PSSi}[\mathrm{M}+\mathrm{H}]^{+}$found, 559.2058; calcd, 559.2058.

\section{1-[2,5,6-Trideoxy-6-(diethoxyphosphinyl)- $\beta$-D-hexofuranosyl]-5-phenyluracil}

(14).

Compound 10 (115 mg, $0.21 \mathrm{mmol})$ was dissolved in THF (1.3 mL). A solution of $1 \mathrm{M}$ TBAF in THF $(0.46 \mathrm{mmol}, 0.46 \mathrm{~mL})$ was added. After stirring for $1 \mathrm{~h}$ at room temperature, the reaction was completed. The solvent was evaporated and the dry residue was purified by column chromatography $\left(\mathrm{CH}_{2} \mathrm{Cl}_{2} / \mathrm{MeOH} 96: 4\right)$ to give pure compound 14 (65 mg, colourless solid) in $71 \%$ yield. ${ }^{1} \mathrm{H}$ NMR (300 MHz, DMSO- $\left.d_{6}\right)$ : $\delta$ $1.18\left(6 \mathrm{H}, \mathrm{dt}, J=1.8 \mathrm{~Hz}, J=6.9 \mathrm{~Hz}, 2 \times \mathrm{OCH}_{2} \mathrm{CH}_{3}\right), 1.75-1.83(4 \mathrm{H}, \mathrm{m}, \mathrm{H}-5$ 'a, H-5'b, H6'a and H-6'b), 2.06-2.14 (1H, m, H-2'a), 2.36-2.51 (1H, m, H-2'b), 3.71-3.72 (1H, m, 
H-4'), 3.89-3.99 (4H, m, 2 x $\left.O \mathrm{CH}_{2} \mathrm{CH}_{3}\right), 4.06-4.12\left(1 \mathrm{H}, \mathrm{m}, \mathrm{H}-3^{\prime}\right), 5.29(1 \mathrm{H}, \mathrm{d}, J=4.5$ Hz, 3'-OH), $6.17\left(1 \mathrm{H}, \mathrm{t}, J=6.9 \mathrm{~Hz}, \mathrm{H}-1^{\prime}\right), 7.29-7.40(3 \mathrm{H}, \mathrm{m}, \mathrm{Ph}), 7.51-7.54(2 \mathrm{H}, \mathrm{m}$, $\mathrm{Ph}), 7.63(1 \mathrm{H}, \mathrm{s}, \mathrm{H}-6) .{ }^{31} \mathrm{P}$ NMR (DMSO- $\left.d_{6}\right): \delta 31.80 .{ }^{13} \mathrm{C}$ NMR $\left(75 \mathrm{MHz}, \mathrm{DMSO}-d_{6}\right)$ : $\delta$ 16.13, $16.20\left(\mathrm{OCH}_{2} \mathrm{CH}_{3}\right), 21.20\left(\mathrm{C}^{\prime} 6^{\prime}, \mathrm{d}, J=139 \mathrm{~Hz}\right), 26.01(\mathrm{C}-5$ ', d, $J=4.7 \mathrm{~Hz})$, 60.82, $\left.60.85\left(\left(\mathrm{OCH}_{2} \mathrm{CH}_{3}\right)_{2}, 2 \mathrm{~d}, J=6.3 \mathrm{~Hz}\right)\right), 72.80$ (C-3'), 84.46 (C-1'), $85.74\left(\mathrm{C}-4^{\prime}\right.$ ', d, $J=17.0 \mathrm{~Hz}), 113.07(\mathrm{C}-5), 114.76,115.04,129.29,129.34,130.23$ and $130.34(\mathrm{Ph})$, 137.87 (C-6), 149.89 (C-6), 162.05 (C-4). Exact mass (ESI-MS) for $\mathrm{C}_{20} \mathrm{H}_{28} \mathrm{~N}_{2} \mathrm{O}_{7} \mathrm{P}$ $[\mathrm{M}+\mathrm{H}]^{+}$found: 439.1639 , calcd: 439.1686 .

\section{1-[2,5,6-Trideoxy-6-(diethoxyphosphinyl)- $\beta$-D-hexofuranosyl]-5-(naphthalen-1-yl)-}

uracil (15). Compound $11(120 \mathrm{mg}, 0.20 \mathrm{mmol})$ was deprotected using the same procedure as described for the synthesis of compound 14. Compound 15 was obtained as a colourless solid in a $65 \%$ yield $(63 \mathrm{mg}) .{ }^{1} \mathrm{H}$ NMR $\left(300 \mathrm{MHz}, \mathrm{CDCl}_{3}\right): \delta 1.17-1.25$ (6H, m, $\left.2 \times \mathrm{OCH}_{2} \mathrm{CH}_{3}\right), 1.77-2.02$ (4H, m, H-5'a, H-5'b, H-6'a and H-6'b), 2.12-2.21 (1H, m, H-2'a), 2.40-2.53 (1H, m, H-2'b), 3.91-4.07 (5H, m, 2 x $\mathrm{OCH}_{2} \mathrm{CH}_{3}$ and $\mathrm{H}-4$ '), 4.16-4.20 (1H, m, H-3'), 5.28 (1H, s, 3'-OH), 6.26 (1H, t, J=6.6 Hz, H-1'), 7.40-7.46 (2H, m, naphthalene), 7.53-7.58 (2H, m, naphthalene), 7.75-7.84 (3H, m, naphthalene), $7.96(1 \mathrm{H}, \mathrm{s}, \mathrm{H}-6) .{ }^{31} \mathrm{P} \mathrm{NMR}\left(\mathrm{CDCl}_{3}\right): \delta 31.46 .{ }^{13} \mathrm{C} \mathrm{NMR}\left(75 \mathrm{MHz}, \mathrm{CDCl}_{3}\right): \delta 16.41$, $16.46\left(\left(\mathrm{OCH}_{2} \mathrm{CH}_{3}\right)_{2}, \mathrm{~d}, J=5.9 \mathrm{~Hz}\right), 22.01(\mathrm{C}-6$ ', d, $J=141 \mathrm{~Hz}), 26.66(\mathrm{C}-5$ ') $40.06(\mathrm{C}-$ 2'), 61.99, $62.06\left(\mathrm{OCH}_{2} \mathrm{CH}_{3}\right)_{2}, 73.85$ (C-3'), 85.43 (C-1'), 86.25 (C-4', d, J= 16.2 Hz), 115.60 (C-5), 126.03, 126.31, 126.36, 127.25, 127.62, 128.09, 128.30, 130.00, 132.88 and 133.34 (naphthalene), 137.17 (C-6), 150.29 (C-6), 162.61 (C-4). Exact mass (ESIMS) for $\mathrm{C}_{24} \mathrm{H}_{30} \mathrm{~N}_{2} \mathrm{O}_{7} \mathrm{P}[\mathrm{M}+\mathrm{H}]^{+}$found: 489.1814, calcd: 489.1785.

\section{1-[2,5,6-Trideoxy-6-(diethoxyphosphinyl)- $\beta$-D-hexofuranosyl]-5-(4-fluorophenyl)-}

uracil (16). Compound 12 (135 mg, $0.24 \mathrm{mmol})$ was deprotected using the same procedure as described for the synthesis of compound 14. Compound 16 was obtained 
as a colourless solid in a $32 \%$ yield $(35 \mathrm{mg}) .{ }^{1} \mathrm{H}$ NMR $\left(300 \mathrm{MHz}, \mathrm{DMSO}-d_{6}\right): \delta 1.18$ $\left(6 \mathrm{H}, \mathrm{dt}, J=2.4 \mathrm{~Hz}, J=6.9 \mathrm{~Hz}, 2\right.$ x $\left.\mathrm{OCH}_{2} \mathrm{CH}_{3}\right), 1.70-1.82$ (4H, m, H-5'a, H-5'b, H-6'a and H-6’b), 2.05-2.13 (1H, m, H-2'a), 2.37-2.44 (1H, m, H-2'b), 3.70-3.71 (1H, m, H4'), 3.89-3.99 (4H, m, 2 x $\left.O \mathrm{CH}_{2} \mathrm{CH}_{3}\right), 4.06-4.09(1 \mathrm{H}, \mathrm{m}, \mathrm{H}-3$ '), $5.28(1 \mathrm{H}, \mathrm{d}, J=4.5 \mathrm{~Hz}$, 3'-OH), 6.16 (1H, t, J= 7.2 Hz, H-1'), 7.17-7.23 (2H, m, subs Ph), 7.55-7.60 (2H, m,

subs $\mathrm{Ph}$ ), $7.64(1 \mathrm{H}, \mathrm{s}, \mathrm{H}-6), 11.53(1 \mathrm{H}, \mathrm{s}, 3-\mathrm{NH}) .{ }^{31} \mathrm{P}$ NMR (DMSO-d $): \delta 31.80 .{ }^{13} \mathrm{C}$ NMR (75 MHz, DMSO-d $\left.d_{6}\right): \delta 16.2,16.3\left(\mathrm{OCH}_{2} \mathrm{CH}_{3}\right), 21.22(\mathrm{C}-6$ ', d, $J=139 \mathrm{~Hz}), 26.11$ (C-5', d, $J=5 \mathrm{~Hz}), 60.99,61.95\left(\left(\mathrm{OCH}_{2} \mathrm{CH}_{3}\right)_{2}, 2 \mathrm{~d}, J=6.1 \mathrm{~Hz}\right), 72.80(\mathrm{C}-3$ '), 84.61 (C1'), 85.86 (C-4', d, $J=16.7 \mathrm{~Hz}), 113.07$ (C-5), 114.76, 115.04, 129.29, 129.34, 130.23 and 130.34 (subs Ph), 137.87 (C-6), 149.89 (C-6), 162.05 (C-4). Exact mass (ESI-MS) for $\mathrm{C}_{20} \mathrm{H}_{27} \mathrm{FN}_{2} \mathrm{O}_{7} \mathrm{P}[\mathrm{M}+\mathrm{H}]^{+}$found, 457.1547; calcd, 457.1534.

\section{1-[2,5,6-Trideoxy-6-(diethoxyphosphinyl)- $\beta$-D-hexofuranosyl]-5-(thiophen-2-yl)-}

uracil (17). Compound 13 (117 $\mathrm{mg}, 0.21 \mathrm{mmol})$ was deprotected using the same procedure as described for the synthesis of compound 14. Compound 17 was obtained as a colourless solid in a 63\% yield $(59 \mathrm{mg}) .{ }^{1} \mathrm{H}$ NMR $\left(300 \mathrm{MHz}, \mathrm{CDCl}_{3}\right): \delta 1.31(6 \mathrm{H}$, app dt, $J=2.1 \mathrm{~Hz}, J=6.9 \mathrm{~Hz}, 2$ x $\left.O \mathrm{CH}_{2} \mathrm{CH}_{3}\right), 1.86-2.08$ (4H, m, H-5'a, H-5'b, H-6'a and H-6'b), 2.18-2.27 (1H, m, H-2'a), 2.46-2.54 (1H, m, H-2’b), 3.97-3.98 (1H, m, H4'), 4.04-4.15 (4H, m, 2 x $\left.\mathrm{OCH}_{2} \mathrm{CH}_{3}\right), 4.19-4.26$ (1H, m, H-3'), 5.30 (1H, s, 3'-OH), $6.25\left(1 \mathrm{H}\right.$, app t, $\left.J=6.6 \mathrm{~Hz}, \mathrm{H}-1^{\prime}\right), 6.97-7.00(1 \mathrm{H}, \mathrm{m}$, thiophene), $7.24(1 \mathrm{H}, \mathrm{d}, J=4.8 \mathrm{~Hz}$, thiophene), $7.36\left(1 \mathrm{H}, \mathrm{d}, J=3.0 \mathrm{~Hz}\right.$, thiophene), $7.69(1 \mathrm{H}, \mathrm{s}, \mathrm{H}-6) .{ }^{31} \mathrm{P} \mathrm{NMR}\left(\mathrm{CDCl}_{3}\right): \delta$ 31.48. ${ }^{13} \mathrm{C}$ NMR $\left(75 \mathrm{MHz}, \mathrm{CDCl}_{3}\right): \delta 16.50,16.58\left(\mathrm{OCH}_{2} \mathrm{CH}_{3}\right)_{2}, 22.05(\mathrm{C}-6$ ', d, $J=142$ Hz), 26.67 (C-5'), 40.27 (C-2'), 62.07, $62.17\left(\mathrm{OCH}_{2} \mathrm{CH}_{3}\right)_{2}, 73.80$ (C-3'), 85.72 (C-1'), 86.40 (C-4', d, $J=15.9 \mathrm{~Hz}), 110.19(\mathrm{C}-5), 124.35,125.45,127.08$ and 133.64 (thiophene), 134.55 (C-6), 149.77 (C-2), 161.52 (C-4). Exact mass (ESI-MS) for $\mathrm{C}_{18} \mathrm{H}_{26} \mathrm{~N}_{2} \mathrm{O}_{7} \mathrm{PS}[\mathrm{M}+\mathrm{H}]^{+}$found, 445.1210; calcd, 445.1193. 


\section{General procedure for the deprotection of 5-modified nucleoside phosphonates}

The phosphonic ester (1 equiv.) was dissolved in $\mathrm{CH}_{2} \mathrm{Cl}_{2}$ under argon. TMSBr (2 equiv.) was added and the resulting solution was stirred overnight. The solvent was evaporated and the residue dissolved in a mixture of $\mathrm{EtOAc}_{\mathrm{Et}} \mathrm{O}(1: 1)$ and water. The organic phase was washed with water and the water layers were combined and lyophilized. Purification of the crude using RP-HPLC (Phenomenex Luna C-18, $\mathrm{H}_{2} \mathrm{O} / 0.1 \% \mathrm{HCOOH}$ in $\mathrm{CH}_{3} \mathrm{CN}, 90: 10 \rightarrow 0: 100$ in $23 \mathrm{~min}$, flow $17.5 \mathrm{~mL} / \mathrm{min}$ ) afforded 2 series of compounds: the $\alpha$ - (retention time $\geq 12 \mathrm{~min}$ ) and $\beta$-isomer (retention time $\approx$ 10-11 $\mathrm{min}$ ) of each phosphonate.

\section{1-[2,5,6-Trideoxy-6-(dihydroxyphosphinyl)- $\beta$-D-hexofuranosyl]-5-phenyluracil (1a)}

and 1-[2,5,6-trideoxy-6-(dihydroxyphosphinyl)-a-D-hexofuranosyl]-5-phenyluracil

(1b) Reaction of compound 14 (27 mg, $0.061 \mathrm{mmol})$ with $\mathrm{TMSBr}(16 \mu \mathrm{L}, 0.12 \mathrm{mmol})$ in $\mathrm{CH}_{2} \mathrm{Cl}_{2}(0.9 \mathrm{~mL})$ as described in the general procedure affording the $\beta$ - $(1 \mathbf{a}, 0.9 \mathrm{mg}$, 4\%) and $\alpha$-isomer (1b, $3.2 \mathrm{mg}, 14 \%)$ as white powders. Compound 1a: ${ }^{1} \mathrm{H}$ NMR (300 MHz, DMSO- $\left.d_{6}\right): \delta$ 1.52-1.55 (2H, m, H-6'a and H-6'b), 1.79-1.91 (2H, m, H-5'a and H-5'b), 2.07-2.11 (1H, m, H-2'a), 2.29-2.38 (1H, m, H-2'b), 3.73 (1H, app s, H-4'), $4.06(1 \mathrm{H}$, app s, H-3'), $6.14(1 \mathrm{H}, \mathrm{t}, J=6.6 \mathrm{~Hz}, \mathrm{H}-1$ ') $)$ 7.27-7.40 (3H, m, Ph), 7.51-7.54 $(2 \mathrm{H}, \mathrm{m}, \mathrm{Ph}), 7.63(1 \mathrm{H}, \mathrm{s}, \mathrm{H}-6) .{ }^{31} \mathrm{P}$ NMR (DMSO-d $): \delta 24.44 .{ }^{13} \mathrm{C}$ NMR $(125 \mathrm{MHz}$, DMSO-d $\left.)_{6}\right): \delta 24.56$ (C-6', d, $J=146$ Hz), 27.22 (C-5'), 38.75 (C-2'), 72.76 (C-3'), 84.30 (C-1'), 86.57 (C-4', d, J=19.3 Hz), 113.89 (C-5), 127.31 (para), 128.10 (ortho), 128.21 (meta), 132.91 (ipsa) (Ph), 137.58 (C-6), 149.86 (C-2), 162.08 (C-4). Exact mass (ESI-MS) for $\mathrm{C}_{16} \mathrm{H}_{18} \mathrm{~N}_{2} \mathrm{O}_{7} \mathrm{P}$ [M-H] found, 381.0836; calcd, 381.0857; Compound 1b: ${ }^{1} \mathrm{H}$ NMR (300 MHz, DMSO-d $)_{6}$ ): $\delta$ 1.49-1.57 (4H, m, H-5'a, H-5'b, H-6'a and H-6'b), 1.98 (1H, app d, $J=14.1 \mathrm{~Hz}, \mathrm{H}-2$ 'a), 2.57-2.65 (1H, m, H-2’b), 4.11 (1H, app s, H-4'), 4.23 (H, app s, H-3'), 6.14 (1H, app d, $J=6.6$ Hz, H-1'), 7.27-7.38 (3H, m, Ph), 7.51- 
$7.54(2 \mathrm{H}, \mathrm{m}, \mathrm{Ph}), 8.16(1 \mathrm{H}, \mathrm{s}, \mathrm{H}-6) .{ }^{31} \mathrm{P}$ NMR (DMSO- $\left.d_{6}\right): \delta 23.62$. Exact mass (ESIMS) for $\mathrm{C}_{16} \mathrm{H}_{18} \mathrm{~N}_{2} \mathrm{O}_{7} \mathrm{P}$ [M-H] found, 381.0851; calcd, 381.0857.

1-[2,5,6-Trideoxy-6-(dihydroxyphosphinyl)-ß-D-hexofuranosyl]-5-(naphtalen-1yl)uracil (2a) and 1-[2,5,6-trideoxy-6-(dihydroxyphosphinyl)-a-D-hexofuranosyl]-5(naphthalen-1-yl)uracil (2b). Reaction of compound 15 (63 mg, $0.13 \mathrm{mmol})$ with $\operatorname{TMSBr}(34 \mu \mathrm{L}, 0.26 \mathrm{mmol})$ in $\mathrm{CH}_{2} \mathrm{Cl}_{2}(1.9 \mathrm{~mL})$ as described in the general procedure affording the $\beta$ - (2a, $7.05 \mathrm{mg}, 13 \%)$ and $\alpha$-isomer $(\mathbf{2 b}, 8.77 \mathrm{mg}, 16 \%)$ as white powders. Compound 2a: ${ }^{1} \mathrm{H}$ NMR (300 MHz, DMSO- $\left.d_{6}\right): \delta 1.47$ (2H, app br s, H-6'a and H-6'b), $1.80(2 \mathrm{H}$, app br s, H-5'a and H-5'b), 2.13 (1H, app br s, H-2'a), 2.27 (1H, app br s, H2’b), 3.79 (1H, app s, H-4'), 4.09-4.14 (1H, m, H-3'), 6.14 (1H, app s, H-1'), 7.49-8.27 $\left(8 \mathrm{H}, \mathrm{m}\right.$, naphthalene and H-6). ${ }^{31} \mathrm{P}$ NMR (DMSO- $\left.d_{6}\right): \delta 20.97$. Exact mass (ESI-MS) for $\mathrm{C}_{20} \mathrm{H}_{20} \mathrm{~N}_{2} \mathrm{O}_{7} \mathrm{P}$ [M-H] ${ }^{-}$found: 431.1041, calcd: 431.1014; Compound 2b: ${ }^{1} \mathrm{H}$ NMR (300 MHz, DMSO- $\left.d_{6}\right): \delta 1.59$ (4H, app br s, H-5'a, H-5'b, H-6'a and H-6'b), 1.99-2.06 (1H, m, H-2'a), 2.52-2.70 (1H, m, H-2’b), 4.13 (1H, app s, H-4'), 4.27 (1H, app s, H-3'), $6.18\left(1 \mathrm{H}\right.$, app d, $\left.J=5.7 \mathrm{~Hz}, \mathrm{H}-1^{\prime}\right), 7.46-7.52$ (2H, m, naphthalene), 7.66 (2H, d, $J=8.4$ $\mathrm{Hz}$, naphthalene), 7.88-7.91 (3H, m, naphthalene), $8.12(1 \mathrm{H}, \mathrm{s}$, naphthalene $), 8.31(1 \mathrm{H}$, s, H-6). ${ }^{31} \mathrm{P}$ NMR (DMSO- $\left.d_{6}\right): \delta 24.28 .{ }^{13} \mathrm{C}$ NMR (75 MHz, DMSO- $\left.d_{6}\right): \delta 72.61$ (C-3'), 85.41 (C-1'), 89.23 (C-4'), 112.48 (C-5), 125.95-132.84 (naphthalene), 139.65 (C-6), 150.02 (C-2), 162.35 (C-4). Exact mass (ESI-MS) for $\mathrm{C}_{20} \mathrm{H}_{20} \mathrm{~N}_{2} \mathrm{O}_{7} \mathrm{P}$ [M-H] found: 431.1009, calcd: 431.1014 .

\section{1-[2,5,6-Trideoxy-6-(dihydroxyphosphinyl)-ß-D-hexofuranosyl]-5-(4-}

fluorophenyl)uracil (3a) and 1-[2,5,6-trideoxy-6-(dihydroxyphosphinyl)-a-Dhexofuranosyl]-5-(4-fluorophenyl)uracil (3b). Reaction of compound 16 (36 mg, $0.078 \mathrm{mmol})$ with $\mathrm{TMSBr}(21 \mu \mathrm{L}, 0.16 \mathrm{mmol})$ in $\mathrm{CH}_{2} \mathrm{Cl}_{2}(1.0 \mathrm{~mL})$ as described in the general affording the $\beta$ - (3a, $1.69 \mathrm{mg}, 6 \%)$ and $\alpha$-isomer $(\mathbf{3 b}, 3.19 \mathrm{mg}, 12 \%)$ as white 
powders. Compound 3a: ${ }^{1} \mathrm{H}$ NMR (300 MHz, DMSO- $\left.d_{6}\right): \delta 1.43(2 \mathrm{H}$, app br s, H-6'a and H-6’b), 1.76 (2H, app br s, H-5'a and H-5'b), 2.09 (1H, app br s, H-2'a), 2.28 (1H, app br s, H-2'b), H-4' under $\mathrm{H}_{2} \mathrm{O}$ peak, 4.08 (1H, app s, H-3'), 6.09 (1H, app s, H-1'), 7.21-7.62 (5H, m, subs Ph and H-6). ${ }^{31} \mathrm{P}$ NMR (DMSO- $\left.d_{6}\right): \delta 20.60$. Exact mass (ESIMS) for $\mathrm{C}_{16} \mathrm{H}_{17} \mathrm{FN}_{2} \mathrm{O}_{7} \mathrm{P}$ [M-H] ${ }^{-}$found: 399.0762, calcd: 399.0763; Compound 3b: ${ }^{1} \mathrm{H}$ NMR (300 MHz, DMSO- $\left.d_{6}\right): \delta$ 1.44-1.58 (4H, m, H-5'a, H-5'b, H-6'a and H-6'b), 1.99 (1H, d, $J=13.5 \mathrm{~Hz}, \mathrm{H}-2$ 'a), 2.52-2.65 (1H, m, H-2’b), 4.11 (1H, app s, H-4'), 4.20-4.25 (1H, m, H-3'), 6.12 (1H, app d, $J=6.9 \mathrm{~Hz}, \mathrm{H}-1^{\prime}$ '), 7.19 (2H, app t, $J=8.7 \mathrm{~Hz}$, subs $\mathrm{Ph}$ ), 7.54-7.59 (2H, m, subs Ph), 8.15 (1H, s, H-6), 8.33 (1H, s, subs Ph). ${ }^{31} \mathrm{P}$ NMR (DMSO$\left.d_{6}\right): \delta 22.19 .{ }^{13} \mathrm{C}$ NMR (75 MHz, DMSO- $\left.d_{6}\right): \delta 72.22$ (C-3’), 85.16 (C-1'), 111.49 (C-5), 114.67, 114.96, 129.57, 129.67 (Ph), 139.00 (C-6), 149.84 (C-2), 162.04 (C-4). Exact mass (ESI-MS) for $\mathrm{C}_{16} \mathrm{H}_{17} \mathrm{FN}_{2} \mathrm{O}_{7} \mathrm{P}[\mathrm{M}-\mathrm{H}]^{-}$found: 399.0743, calcd: 399.0763.

\section{1-[2,5,6-Trideoxy-6-(dihydroxyphosphinyl)- $\beta$-D-hexofuranosyl]-5-(thiophen-2-}

yl)uracil (4a) and 1-[2,5,6-trideoxy-6-(dihydroxyphosphinyl)-a-D-hexofuranosyl]-5(thiophen-2-yl)uracil (4b). Reaction of compound 17 (59 mg, $0.13 \mathrm{mmol}$ ) with TMSBr (35 $\mu \mathrm{L}, 0.27 \mathrm{mmol})$ in $\mathrm{CH}_{2} \mathrm{Cl}_{2}(2.0 \mathrm{~mL})$ as described in the general procedure affording the $\beta$ - (4a, $5.2 \mathrm{mg}, 10 \%)$ and $\alpha$-isomer (4b, $9.6 \mathrm{mg}, 19 \%)$ as white powders. Compound 4a: ${ }^{1} \mathrm{H}$ NMR (300 MHz, DMSO- $\left.d_{6}\right): \delta 1.50$ (2H, app br s, H-6'a and H-6'b), $1.80(2 \mathrm{H}$, app br s, H-5'a and H-5'b), 2.04-2.12 (1H, m, H-2'a), 2.27-2.31 (1H, m, H-2'b), 3.80 (1H, app br s, H-4'), 4.09 (1H, app br s, H-3'), 6.10 (1H, d, J=6.6 Hz, H-1'), $7.06(1 \mathrm{H}$, t, $J=4.8 \mathrm{~Hz}$, thiophene), $7.45(2 \mathrm{H}$, app dd, $J=4.8 \mathrm{~Hz}, J=14.4 \mathrm{~Hz}$, thiophene), $7.89(1 \mathrm{H}$, s, H-6). ${ }^{31} \mathrm{P}$ NMR (DMSO- $\left.d_{6}\right): \delta 23.13 .{ }^{13} \mathrm{C}$ NMR $\left(75 \mathrm{MHz}, \mathrm{CDCl}_{3}\right): \delta(\mathrm{C}-6, \mathrm{C}-5$ ' and C-2' not visible), 73.42 (C-3'), 85.35 (C-1'), 109.21 (C-5), 123.93, 126.37, 127.43,134.26 (thiophene), 135.74 (C-6), 149.97 (C-2), 161.94 (C-4). Exact mass (ESIMS) for $\mathrm{C}_{14} \mathrm{H}_{16} \mathrm{~N}_{2} \mathrm{O}_{7} \mathrm{PS}$ [M-H] found:387.0377, calcd: 387.0421; Compound 4b: ${ }^{1} \mathrm{H}$ 
NMR (300 MHz, DMSO- $\left.d_{6}\right)$ : $\delta$ 1.40-1.72 (4H, m, H-5'a, H-5'b, H-6'a and H-6'b), 2.02 (1H, app d, $J=14.4 \mathrm{~Hz}, \mathrm{H}-2$ 'a), 2.59-2.68 (1H, m, H-2’b), 4.13 (1H, app d, $J=4.8 \mathrm{~Hz}$, H-3’), 4.27 (4H, app s, H-4'), 6.16 (1H, app d, $J=5.7$ Hz, H-1'), 7.04-7.07 (1H, dd, $J=$ 3.6 Hz, $J=4.8 \mathrm{~Hz}$, thiophene), 7.37-7.38 (1H, m, thiophene), 7.44-7.45 (1H, m, thiophene), $8.46(1 \mathrm{H}, \mathrm{s}, \mathrm{H}-6) .{ }^{31} \mathrm{P}$ NMR (DMSO- $\left.d_{6}\right): \delta 25.63 .{ }^{13} \mathrm{C} \mathrm{NMR}(75 \mathrm{MHz}$, DMSO- $\left.d_{6}\right): \delta 24.29\left(\mathrm{C}-6^{\prime}, \mathrm{d}, J=135 \mathrm{~Hz}\right), 27.01$ (C-5'), (C-2' under DMSO peak), 72.59 (C-3'), 85.51 (C-1'), 88.91 (C-4', d, $J=15.7$ Hz), 107.71 (C-5), 122.58, 125.47, 126.54,134.28 (thiophene), 136.98 (C-6), 149.53 (C-2), 161.87 (C-4). Exact mass (ESIMS) for $\mathrm{C}_{14} \mathrm{H}_{16} \mathrm{~N}_{2} \mathrm{O}_{7} \mathrm{PS}[\mathrm{M}-\mathrm{H}]^{-}$found: 387.0416, calcd: 387.0421 .

1-[2,5,6-Trideoxy-6-(diethoxyphosphinyl)- $\beta$-D-hexofuranosyl]-uracil

(18).

Compound 8 (309 mg, $0.65 \mathrm{mmol}$ ) was dissolved in $4.1 \mathrm{~mL}$ THF and a TBAF solution in THF (1M, $1.44 \mathrm{~mL}, 1.44 \mathrm{mmol})$ was added at $\mathrm{rt}$. After stirring for $3 \mathrm{~h}$ the reaction mixture was evaporated in vacuo and poured on a silica column $\left(\mathrm{CH}_{2} \mathrm{Cl}_{2} / \mathrm{MeOH} 92: 8\right)$ to give compound 18 (162 mg, 69\%) as a colourless solid. ${ }^{1} \mathrm{H}$ NMR (300 MHz, DMSO$\left.d_{6}\right): \delta 1.23\left(6 \mathrm{H}, \mathrm{t}, J=6.9 \mathrm{~Hz}, 2 \times \mathrm{OCH}_{2} \mathrm{CH}_{3}\right), 1.68-1.82(4 \mathrm{H}, \mathrm{m}, \mathrm{H}-5$ ' a, H-5'b, H-6'a and H-6’b), 2.04-2.24 (2H, m, H-2'a and H-2”), 3.66-3.68 (1H, m, H-4'), 3.92-4.08 (5H, m, $2 \times \mathrm{OCH}_{2} \mathrm{CH}_{3}$ and $\left.\mathrm{H}^{-} 3^{\prime}\right), 5.30\left(1 \mathrm{H}, \mathrm{d}, J=4.5 \mathrm{~Hz}, 3^{\prime}-\mathrm{OH}\right), 5.63(1 \mathrm{H}, \mathrm{d}, J=8.7 \mathrm{~Hz}$, $\mathrm{CH}=\mathrm{CH}), 6.10\left(1 \mathrm{H}, \mathrm{t}, J=6.6 \mathrm{~Hz}, \mathrm{H}-1^{\prime}\right), 7.58(1 \mathrm{H}, \mathrm{d}, J=7.8 \mathrm{~Hz}, \mathrm{CH}=\mathrm{CH}), 11.31(1 \mathrm{H}, \mathrm{s}$, 3-NH). ${ }^{31} \mathrm{P}$ NMR (DMSO- $\left.d_{6}\right): \delta 31.89 .{ }^{13} \mathrm{C}$ NMR (75 MHz, DMSO- $\left.d_{6}\right): \delta 16.26,16.33$ $\left(\mathrm{OCH}_{2} \mathrm{CH}_{3}\right), 21.07$ (C-6', d, $\left.J=139 \mathrm{~Hz}\right), 25.95$ (C-5', d, $\left.J=4.1 \mathrm{~Hz}\right), 60.93,60.96$ $\left(\mathrm{OCH}_{2} \mathrm{CH}_{3}, \mathrm{~d}, J=6.3 \mathrm{~Hz}\right), 72.52\left(\mathrm{C}-3^{\prime}\right), 83.65\left(\mathrm{C}-1^{\prime}\right), 85.43\left(\mathrm{C}^{\prime} 4^{\prime}, J=16.8 \mathrm{~Hz}\right), 102.08$ (C-5), 140.79 (C-6), 150.45 (C-2), 163.10 (C-4). Exact mass (ESI-MS) for $\mathrm{C}_{14} \mathrm{H}_{24} \mathrm{~N}_{2} \mathrm{O}_{7} \mathrm{P}[\mathrm{M}+\mathrm{H}]^{+}$found, 363.1308; calcd, 363.1316.

1-[2,5,6-Trideoxy-6-(dihydroxyphosphinyl)-ß-D-hexofuranosyl]-uracil (5a) and 1[2,5,6-trideoxy-6-(dihydroxyphosphinyl)-a-D-hexofuranosyl]-uracil (5b). To a 
solution of 18 (40 mg, $0.11 \mathrm{mmol})$ in $\mathrm{CH}_{2} \mathrm{Cl}_{2}(1.6 \mathrm{~mL})$ was added $\mathrm{TMSBr}(29 \mu \mathrm{L}, 0.22$ mmol). After stirring overnight, the volatiles were removed in vacuo. The residue was dissolved in water, washed with EtOAc/Et ${ }_{2} \mathrm{O}(1: 1)$ and lyophilized. A 3:2 mixture of the $\alpha$ - and $\beta$-isomer (25 mg, 65\%) was obtained as a yellow powder. ${ }^{1} \mathrm{H}$ NMR (300 MHz, $\left.\mathrm{D}_{2} \mathrm{O}\right): \delta$ 1.48-1.91 (4.4H, m, H-5'a, H-5'b, H-6'a, H-6'b and minor isomer H-2'a), 2.12$2.17(0.6 \mathrm{H}$, major isomer, $\mathrm{m}, \mathrm{H}-2$ ' $\mathrm{b}), 2.34-2.38(0.6 \mathrm{H}$, major isomer, $\mathrm{m}, \mathrm{H}-2$ 'a $), 2.72-$ $2.80\left(0.4 \mathrm{H}\right.$, minor isomer, $\left.\mathrm{m}, \mathrm{H}-2^{\prime} \mathrm{b}\right), 3.94-4.00\left(0.4 \mathrm{H}\right.$, minor isomer, $\left.\mathrm{m}, \mathrm{H}-3^{\prime}\right), 4.31$ $4.37\left(1.6 \mathrm{H}, \mathrm{m}\right.$, major isomer $\mathrm{H}-3^{\prime}$ and $\left.\mathrm{H}-4^{\prime}\right), 5.85(0.6 \mathrm{H}$, major isomer, $\mathrm{d}, J=7.8 \mathrm{~Hz}$, $\mathrm{CH}=\mathrm{CH}), 5.89(0.4 \mathrm{H}$, minor isomer, $\mathrm{d}, J=8.1 \mathrm{~Hz}, \mathrm{CH}=\mathrm{CH}), 6.15(0.6 \mathrm{H}$, major isomer, dd, $\left.J=2.7 \mathrm{~Hz}, J=7.5 \mathrm{~Hz}, \mathrm{H}-1^{\prime}\right), 6.25\left(0.4 \mathrm{H}\right.$, minor isomer, app t, $\left.J=6.9 \mathrm{~Hz}, \mathrm{H}-1^{\prime}\right), 7.73$ $(0.4 \mathrm{H}$, minor isomer, $\mathrm{d}, J=8.4 \mathrm{~Hz}, \mathrm{CH}=\mathrm{CH}), 7.93(0.6 \mathrm{H}$, major isomer, $\mathrm{d}, J=8.1 \mathrm{~Hz}$, $\mathrm{CH}=\mathrm{CH}) .{ }^{31} \mathrm{P}$ NMR $\left(\mathrm{DMSO}-d_{6}\right): \delta 23.63 .{ }^{13} \mathrm{C} \mathrm{NMR}\left(75 \mathrm{MHz}, \mathrm{DMSO}-d_{6}\right): \delta 25.53$ (major isomer, C-6', d, $J=134 \mathrm{~Hz}$ ), 27.24 (minor isomer, C-6', d, $J=128 \mathrm{~Hz}$ ), 72.72 (major isomer, C-3'), 72.86 (minor isomer, C-3'), 83.86 (minor isomer, C-1'), 85.25 (major isomer, C-1'), 87.17 (minor isomer C-4', d, $J=15.2 \mathrm{~Hz}$ ), 89.09, (major isomer, C-4', d, $J=13.7 \mathrm{~Hz}$ ), 101.13 (major isomer, C-5), 102.33 (minor isomer, C-5), 140.64 (minor isomer, C-6), 141.67 (major isomer, C-6), 150.62 (minor isomer, C-2), 150.74 (major isomer, C-2), 163.29 (minor isomer, C-4), 163.56 (major isomer, C-4). Exact mass (ESI-MS) for $\mathrm{C}_{10} \mathrm{H}_{14} \mathrm{~N}_{2} \mathrm{O}_{7} \mathrm{P}$ [M-H] $]^{-}$found, 305.0539; calcd, 305.0544.

Experimental assay. Antiviral and cytotoxicity assays for compounds 1a-4b. The antiviral activity of the new compounds was determined using a cytopathogenicity assay against herpes simplex virus type 1 (HSV-1) (KOS strain), herpes simplex virus type 2 (HSV-2) (G strain), vaccinia virus, vesicular stomatitis virus, $\mathrm{HSV}-1 \mathrm{TK}^{-} \mathrm{KOS} \mathrm{ACV}^{\mathrm{r}}$ in HEL cell cultures. Stock solutions of the test compounds were prepared in DMSO at a concentration of $10 \mathrm{mg} / \mathrm{mL}$. Cells, grown to confluency in 96-well plates, were infected 
with $100 \mathrm{CCID}_{50}$ of virus, one $\mathrm{CCID}_{50}$ being the $50 \%$ cell culture infective dose in the presence of varying concentrations of the test compounds. Cultures were further incubated until complete cytopathogenicity was observed in the infected and untreated virus control. The cytotoxicity of the compounds was evaluated in parallel with their antiviral activity in uninfected cells and is expressed as the minimum cytotoxic concentration (MCC) that causes a microscopically detectable alteration of normal cell morphology. The symbol " $>$ ' is used to indicate the highest concentration at which the compounds were tested and found not to be antivirally active.

For the anti-HCMV and anti-VZV assays, HEL fibroblasts were infected with 100 PFU per well. Compounds were added after a $1 \mathrm{~h}$-incubation period, and the cells were further incubated at $37^{\circ} \mathrm{C}$. After 5 (VZV) and 7 days (HCMV) of incubation, plaques (VZV) or virus-induced cytopathogenicity (HCMV) was monitored microscopically after ethanol fixation and staining with Giemsa solution. The cytotoxicity of the compounds was evaluated in parallel with their antiviral activity in uninfected cells and is expressed as the minimum cytotoxic concentration that causes a microscopically detectable alteration of cell morphology (MCC) and the concentration required to reduce cell growth by $50 \%\left(\mathrm{CC}_{50}\right)$.

Determination of the anti-HIV activity of the compounds was based on virus-induced cytopathogenicity of HIV-infected CEM cells, measured at day 4 to 5 post virus infection by microscopically estimating virus-induced syncytia formation. Results are expressed as the $50 \%$ effective concentration $\left(\mathrm{EC}_{50}\right)$ as reported in Table IV.3. The cytostatic activity of the compounds was evaluated in parallel with their antiviral activity in uninfected cell cultures and is expressed as the $50 \%$-inhibitory concentration for the proliferation of the T-lymphocyte CEM cells $\left(\mathrm{EC}_{50}\right)$. 
Figure 1. 2'-Deoxyuridine and envisaged analogues.

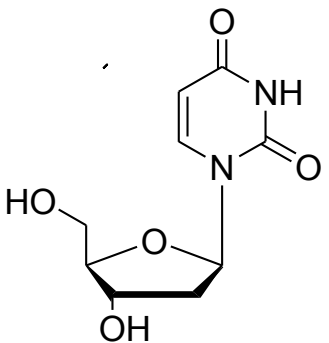

2'-deoxyuridine<smiles>[R]c1cn(C2CC(O)C3COC2C3)c(=O)[nH]c1=O</smiles>

$\mathrm{R}=$ heteroaromatic substituent

Scheme 1. Synthesis of 5-modified 2'-deoxyuridine phosphonate analogues. Reagents and conditions: (a) 2'-Iodoxybenzoic acid, $\mathrm{CH}_{3} \mathrm{CN}, \quad 80 \quad{ }^{\circ} \mathrm{C}, \quad 6 \quad$ h; $\quad$ (ii) [(diethoxyphosphinyl)methyl]triphenylphosphorane, DMSO, rt, 20 h, 41\% over 2 steps; (b) $\mathrm{H}_{2}, \mathrm{Pd} / \mathrm{C}, \mathrm{MeOH}, \mathrm{rt}$, overnight, 97\%; (c) NBS, DMF, rt, overnight, 49\%; (d) R$\mathrm{B}(\mathrm{OH})_{2}, \mathrm{Na}_{2} \mathrm{CO}_{3}, \mathrm{Pd}\left(\mathrm{PPh}_{3}\right)_{4}, \mathrm{DMF}, \mathrm{H}_{2} \mathrm{O}$, reflux, 4 h, 75-91\%; (e) $1 \mathrm{M}$ TBAF in THF, rt, $1 \mathrm{~h}, 32-71 \%$; (f) $\mathrm{TMSBr}, \mathrm{CH}_{2} \mathrm{Cl}_{2}$, rt, overnight, 4-19\%. 


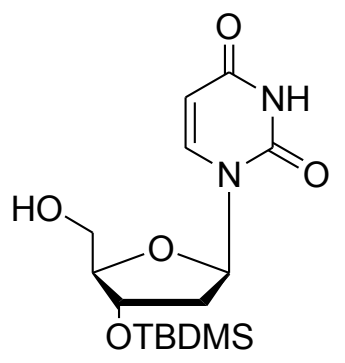

6

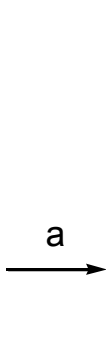<smiles>CCOP(=O)(CCC1OC2CC(C)CC1O2)OCC</smiles>

8

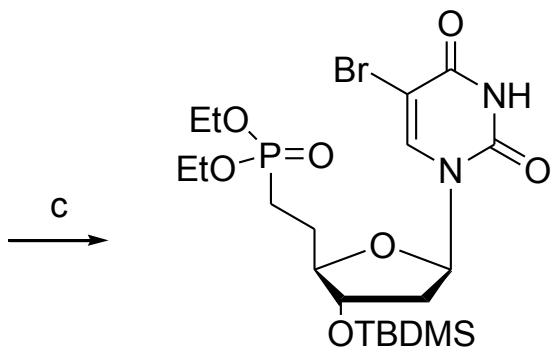

9<smiles>[R]c1cn(C2COCCC2OCC)c(=O)[nH]c1=O</smiles>

$\stackrel{\mathrm{e}}{\longrightarrow}$<smiles></smiles>

14-17

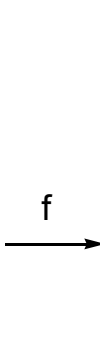<smiles></smiles>

1a: $R=$ phenyl

2a: $R=$ naphthalen-1-yl

3a: $R=4$-fluorophenyl 4a: $R=$ thiophen-2-yl

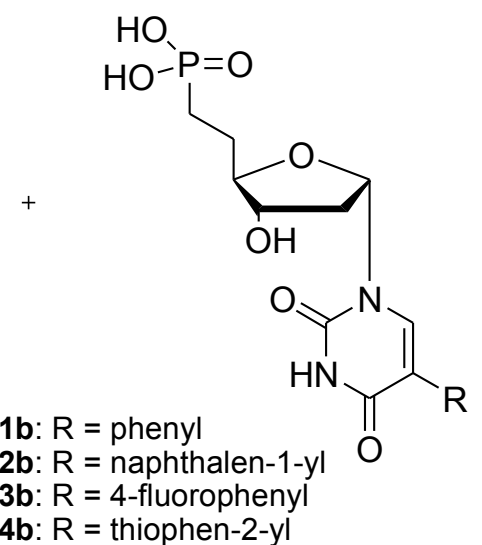


Scheme 2. Synthesis of non-modified 2'-deoxyuridine phosphonate analogue 5a. Reagents and conditions: (a) $1 \mathrm{M}$ TBAF in THF, rt, 3 h, 69\%; (b) $\mathrm{TMSBr}, \mathrm{CH}_{2} \mathrm{Cl}_{2}$, rt, overnight, $65 \%$.

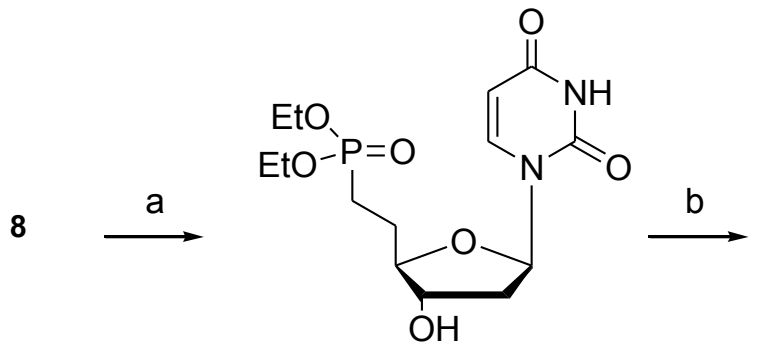

18<smiles>O=c1ccn(C2C[C@H]3O[C@@H](CCP(=O)(O)O)[C@@H]2O3)c(=O)[nH]1</smiles>

$5 a$

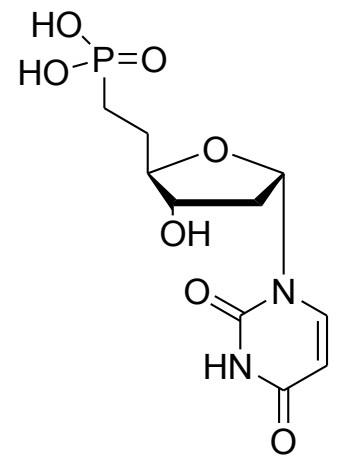

$5 b$

Figure 2. 2D ROESY (500.13 MHz, 298.0 K) spectrum of compound 1a

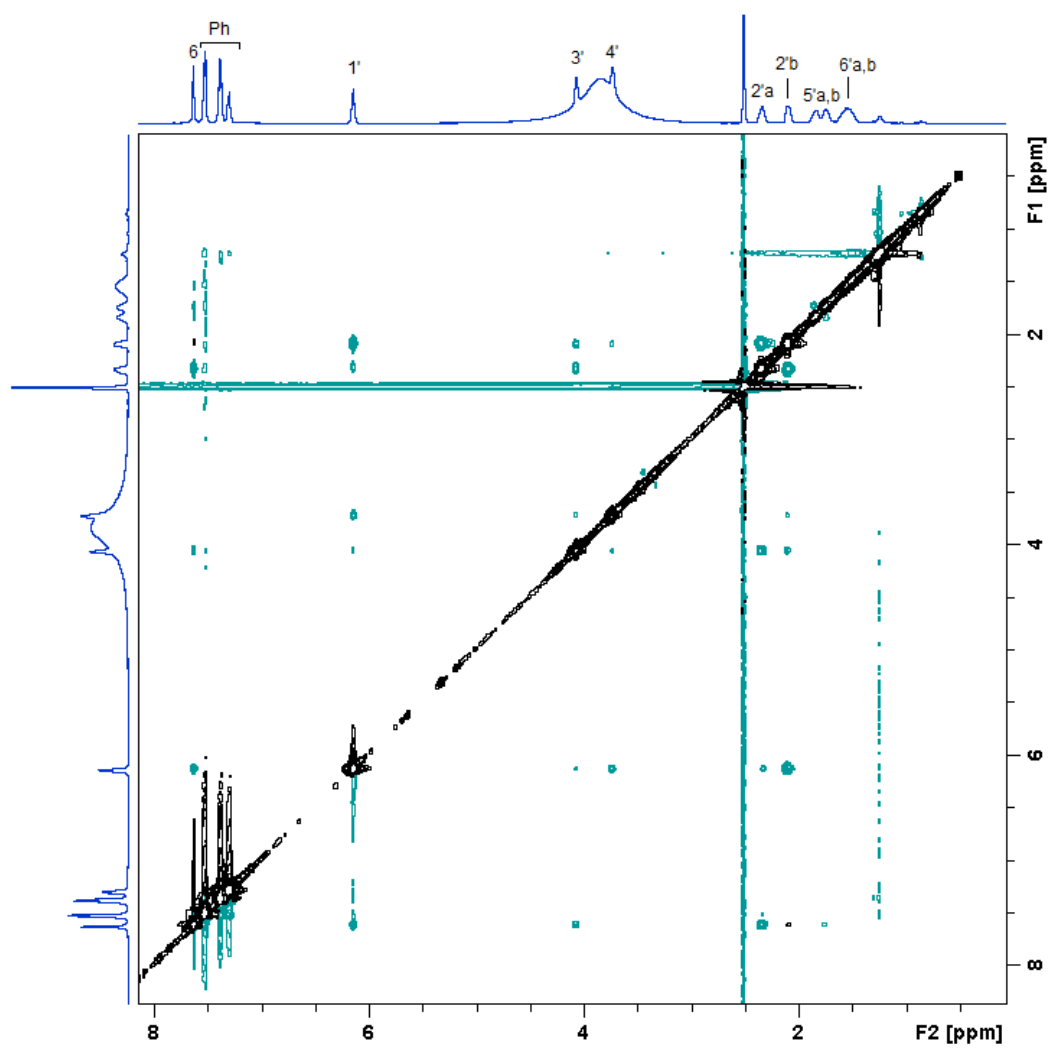


Table 1. Antiviral activity and cytotoxicity of 5-modified 2'-deoxyuridine phosphonate analogues against different HCMV and VZV strains in HEL cell cultures.

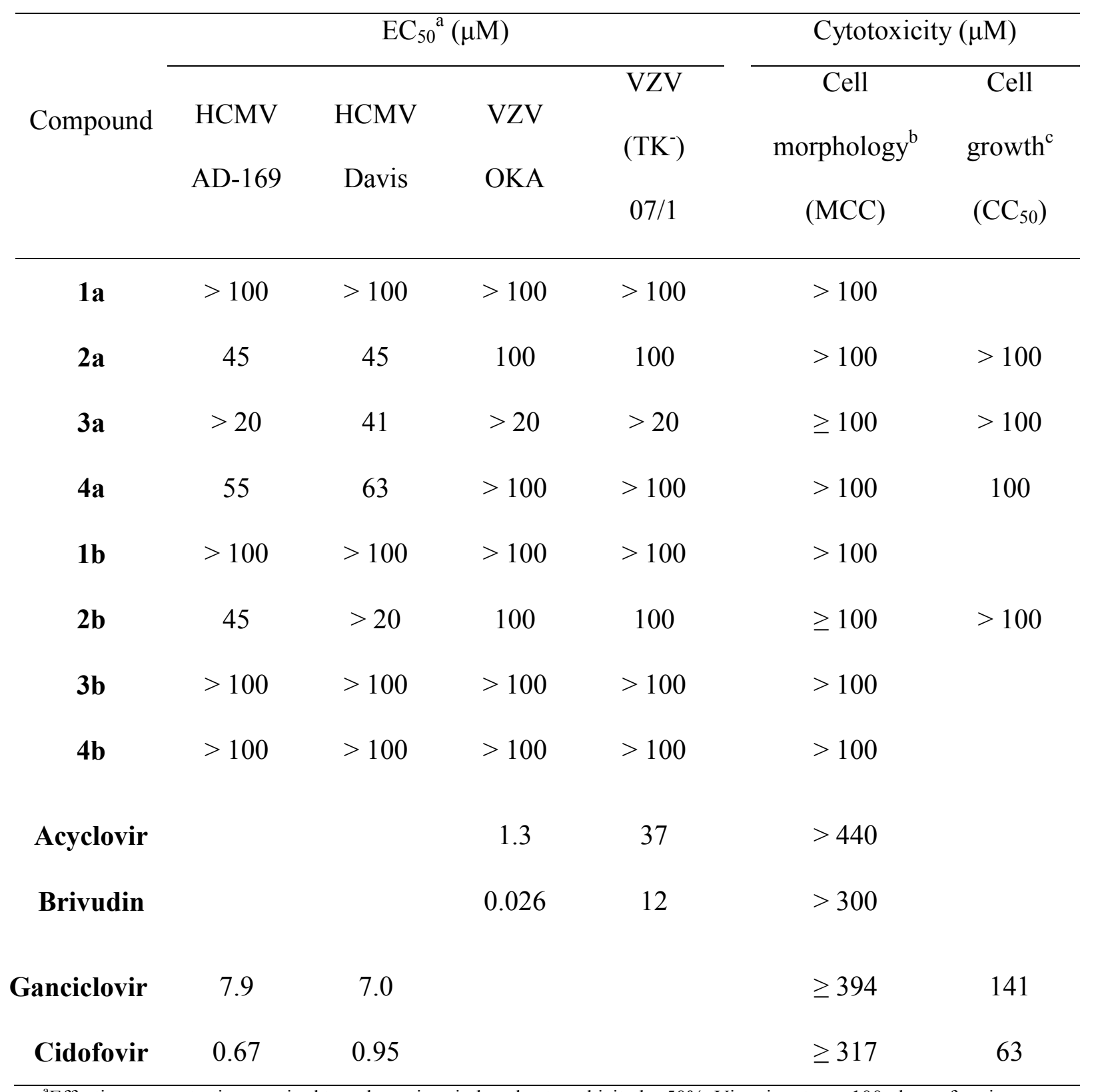

${ }^{\mathrm{a}}$ Effective concentration required to reduce virus-induced cytopathicity by $50 \%$. Virus input was 100 plaque forming units (PFU).

${ }^{b}$ Minimum cytotoxic concentration or compound concentration that caused a microscopically detectable alteration of cell morphology. 
${ }^{\mathrm{c}} 50 \%$-Cytotoxic concentration or compound concentration required to reduce cell growth by $50 \%$.

\section{References}

${ }^{1}$ De Clercq, E. and Holý, A. Acyclic nucleoside phosphonates: a key class of antiviral drugs. Nat. Rev. Drug Discov. 2005, 4, 928-940.

2 Brulikova, L. and Hlavac, J. Synthesis, reactivity and biological activity of 5alkoxymethyluracil analogues. Beilstein J. Org. Chem. 2011, 7, 678-698.

${ }^{3}$ Ivanov, A. V.; Simonyan, A. R.; Belanov, E. F. and Aleksandrova, L. A. Synthesis and antiviral activity of new 5-substituted 2'-deoxyuridine derivatives. Russ. J. Bioorg. Chem. 2005, 31, 556-562.

${ }^{4}$ Wigerinck, P.; Kerremans, L.; Claes, P.; Snoeck, R.; Maudgal, P.; De Clercq, E. and Herdewijn, P. Synthesis and antiviral activity of 5-thien-2-yl-2“-deoxyuridine analogues. $J$. Med. Chem. 1993, 36, 538-543. 
${ }^{5}$ Sastry, J. K.; Nehete, P. N.; Khan, S.; Nowak, B. J.; Plunkett, W.; Arlinghaus, R. B. and Farquhar, D. Membrane-permeable dideoxyuridine 5'-monophosphate analog inhibits human-immunodeficiency-virus infection. Mol. Pharmacol. 1992, 41, 441-445.

${ }^{6}$ Puech, F.; Gosselin, G.; Lefebvre, I.; Pompon, A.; Aubertin, A. M.; Kirn, A. and Imbach, J. L. Intracellular delivery of nucleoside monophosphates through a reductase-mediated activation process. Antiviral Res. 1993, 22, 155-174.

${ }^{7}$ Fries, K. M.; Joswig, C. and Borch, R. F. Synthesis and biological evaluation of 5-fluoro-2'deoxyuridine phosphoramidate analogs. J. Med. Chem. 1995, 38, 2672-3680.

${ }^{8}$ Cosyn, L.; Van Calenbergh, S.; Joshi, B. V.; Ko, H.; Carter, R. L.; Harden, T. K. and Jacobson, K. A. Synthesis and P2Y receptor activity of nucleoside 5'-phosphonate derivatives. Bioorg. Med. Chem. Lett. 2009, 19, 3002-3005.

${ }^{9}$ Rai, D.; Johar, M.; Srivastav, N. C.; Manning, T.; Agrawal, B.; Kunimoto, D. Y. and Kumar, R. Inhibition of Mycobacterium tuberculosis, Mycobacterium bovis, and Mycobacterium avium by Novel Dideoxy Nucleosides J. Med.Chem. 2007, 50, 4766-4774.

${ }^{10}$ Pomeisl, K.; Holý, A. and Pohl, R. Pd-catalyzed Suzuki-Miyaura coupling reactions in the synthesis of 5-aryl-1-[2-(phosphonomethoxy)ethyl]uracils as potential multisubstrate inhibitors of thymidine phosphorylase. Tetrahedron Lett. 2007, 48, 3065-3067.

${ }^{11}$ Van Aerschot, A.; Jie, L. and Herdewijn, P. Synthesis of 5'-O-phosphonomethyl-2',3'didehydro-2',3'-dideoxyuridine by use of P-methoxybenzyl as a $\mathrm{N}^{3}$-protecting group. Tetrahedron Lett. 1991, 32, 1905-1908. 